\title{
Cultivating on Autonomous Learning Ability in English Teaching
}

\author{
Xiuhui Hao \\ College of Foreign Languages, Bohai University, Jinzhou, 121013, China \\ gloryqiushi@163.com
}

Keywords: English teaching; autonomous learning; teacher role; cultivating strategies

\begin{abstract}
As the teacher-centric to impart knowledge and skill of teaching ideas, convert to the student-centric study not only impart knowledge of the language, pay more attention to the teaching of ideological transformation training of language application ability and learning ability, is the aim of College English teaching reform. Based on the theory of autonomous learning, it constructs the autonomous learning process, analyzes the teacher's role in autonomous learning, and puts forward the strategies for developing autonomous learning ability in English teaching in this paper. Specific strategies include cultivating students' awareness of autonomous learning, actively guiding students' autonomous learning, giving full play to the role of process assessment, cultivating metacognitive strategies and promoting autonomous learning. The research results of this paper play an important role in promoting the formation of students' individualized learning methods and the development of students' autonomous learning ability.
\end{abstract}

\section{Introduction}

Autonomous learning is an active and conscious learning behavior of students in the process of learning. Based on the students' intrinsic learning motivation "want to learn "; they are based on the students' mastery of "certain learning strategies", and set up the "persistence" based on the will effort. Cultivation of autonomous learning ability is a system engineering, teachers need to change the concept of teaching, research learning rules and explore the new teaching strategy, seeking to cultivate the teaching mode, content and methods of learning autonomous learning ability. Under the guidance of the teacher, the students can enhance their awareness of autonomous learning, master their learning methods and develop their study habits.

Compared with passive acceptance learning, autonomous learning has the following three characteristics: first, the initiative of learning. It includes the purpose, selectivity and self-regulation of individual behavior. It emphasizes the cultivation of students' strong learning motivation and strong interest in learning, in order to stimulate and maintain the initiative of learning, and students can act rationally according to their own conditions and adjust themselves in a timely manner. Second, the creativity of learning. Creativity is the essential characteristic of autonomous learning, and it is also a manifestation of subjectivity. Autonomous learning is based on its own knowledge and experience, and endows knowledge with personal meaning. It is a kind of creative learning. Third, the autonomy of learning. In the process of autonomous learning, students have more opportunities to study independently, and have more time to think, to ask questions and to solve problems. Students can also choose their own learning methods according to their learning goals, learning characteristics and learning conditions, control the learning process, and creatively solve problems in learning.

One of the aims of the reform of English teaching mode is to promote the formation of students' individualized learning methods and the development of students' autonomous learning ability. The new teaching model should enable students to choose materials and methods suitable for their own needs to study, acquire guidance of learning strategies, and gradually improve their ability to learn independently. From the teacher centered, simply to impart knowledge and skills of teaching thoughts and practice, to take the student as the center, not only teach the language knowledge and skills, pay more attention to the change of training the ability of language application ability of 
autonomous learning and teaching thought and practice, but also the transformation of students' lifelong education and learning ability oriented to in order to cultivate.

\section{Theoretical Basis of Autonomous Learning}

The theoretical foundation of autonomous learning ability includes humanism, cognition and constructivism. These three theories all emphasize learner centered. It is under the influence of these three theories that the concept of independent learning can be formed.

(1) Humanistic learning theory. Humanistic learning theory is based on humanistic psychology. In the process of learning, students are the main body and teachers are the facilitators. We should pay attention to the needs, emotions and wishes of the learners in the course of learning. It is a practical study, a life that integrates learning with experience, and fully mobilizes the enthusiasm of students. For learners to create a good environment, so that they perceive the world from their own point of view, to achieve the understanding of the world, to achieve the highest level of self-realization. The theory of learner autonomy originates from the idea of humanistic learning, and it is the most direct embodiment of humanism.

(2) Cognitive learning theory. It is considered that autonomous learning is the re-organization of learners' cognitive structure, emphasizing the initiative of students' learning, emphasizing the intrinsic motivation of learners' learning, and emphasizing the independent thinking of learners. In opposition to traditional teaching, teachers control students' learning and restrict their autonomy. The theory of cognitive learning requires students to process their knowledge autonomously, to monitor themselves, and to take responsibility for their learning. To help students to determine their own learning goals, select learning strategies, acquire knowledge based on the existing knowledge, and promote the further development of the theory of independent learning.

(3) Constructivism learning theory. On the basis of cognitive developmental psychology and social interaction theory, constructivism is produced. The role of beliefs, external experiences, and psychological structures in the construction of knowledge. It is considered that teachers, students, tasks and environment are essential factors in teaching. Emphasizing the individual differences among learners and paying attention to the interaction among teachers, students, tasks and environment in the process of teaching, it promotes the development of cognitive learning theory and social interaction learning theory, and is the direct embodiment of humanistic learning theory. The theory of social constructivist learning reflects the strategy of autonomous learning with group and project as the center.

\section{Autonomous Learning Process}

Student independent learning is based on teacher support service and interactive learning is the main way. The specific process is shown in Fig. 1.

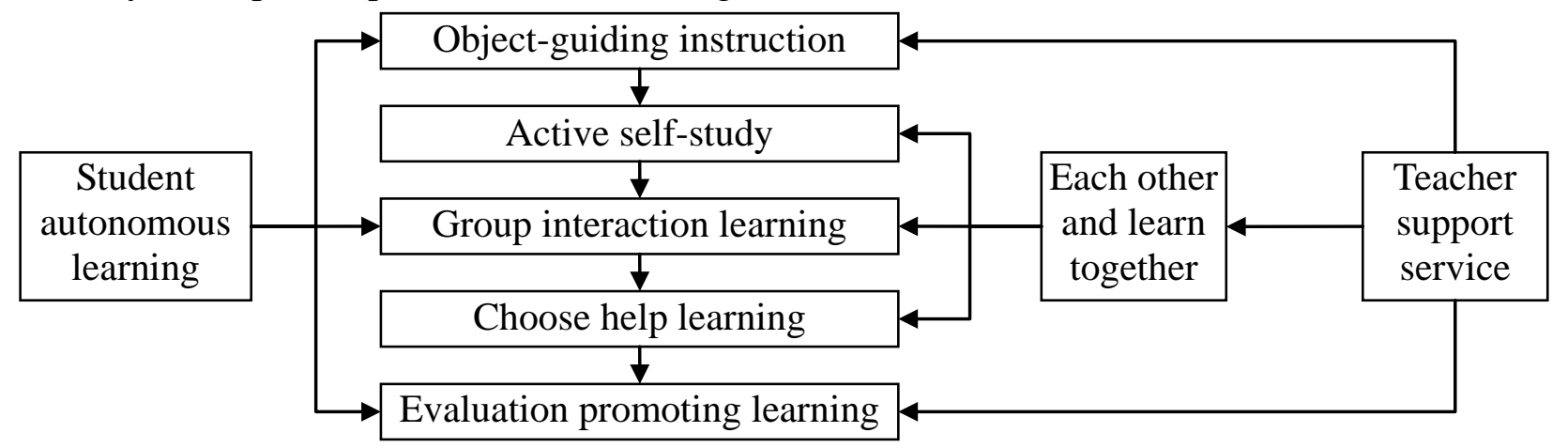

Fig. 1. Autonomous learning process

(1) Object-guiding instruction. This is the beginning of classroom teaching. In the beginning of classroom teaching, students should be given specific guidance to prepare students for their own study. Through target guidance, students are introduced into the preparation state. 
(2) Active self-study. This is the central link of classroom teaching. On the basis of "Object-guiding instruction", students can enter the "Active self-study" state by creating scenarios. This part requires students to study independently and explore independently. Students are the main body, and the service provided by teachers is mainly to help students grasp the ideas and methods of learning content.

(3) Group interaction learning. This is the key link of classroom teaching. Through the "Group interaction learning", not only shows the achievements and experience of "Active self-study", and through the discussion and exchange, interactive Q \& A; , a preliminary solution of middle school students "Active self-study" link to problems they cannot solve, make learning to the depth development.

(4) Choose help learning. This is an innovative part of classroom teaching. "Group interaction learning" left a variety of problems in this link to solve. Students can choose the types of teacher support services independently, and use the learning resources and conditions provided by teachers to study and explore, and to train students' creative decision-making ability.

(5) Evaluation promoting learning. Students evaluate their learning content, develop good habits of self-induction, self-feedback and self-regulation, and become practitioners of "Lifelong learning". The teacher sums up the classroom study, evaluates the teaching effect, and further strengthens and strengthens the students' learning results.

\section{Teacher Role in English Autonomous Learning}

The traditional teaching mode gives full play to the role of "preaching, teaching and solving doubts". The teacher is the authority of knowledge, the teaching process is teacher oriented, the students are passive receivers, and the teaching centers are teachers, books and classrooms". Between teachers and students is a simple relationship between transmission and acceptance, teachers teach knowledge and skills to help students answer doubts. Since the period of teachers on the role very well, but there is a serious shortage of teachers: emphasis on social responsibility, ignore the individual life value and demand of teachers; emphasize teachers' rights and roles, ignoring the teachers and students relations of cooperation; Emphasize the professional ability of teachers, neglect the cultivation of people's professional consciousness, emphasize the transfer of teacher knowledge, and ignore the creativity of teaching and learning.

English teaching is a monotonous process from "teaching" to "accepting". This one-way transmission approach emphasizes language knowledge, ignores language ability and attitudes, and influences the students' enthusiasm for learning English. The autonomous learning centered English teaching mode, teachers should change the traditional idea, objective understanding of their role, although the autonomy of the students has been enhanced, the role of teachers has not decreased, but diversified. The English teaching mode of autonomous learning, English teaching is a process of language practice students initiative, teachers should help determine learning goals, select learning content and schedule, choosing learning methods and skills, monitoring the learning process and evaluate learning effect. English teachers play six major roles, as shown in Fig. 2.

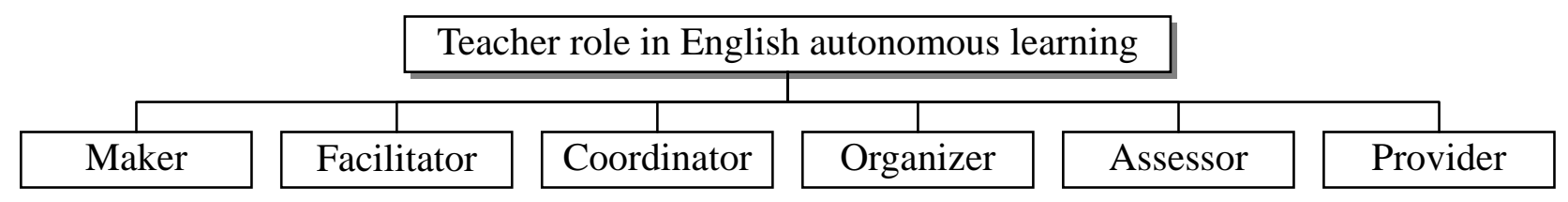

Fig. 2. Teacher role in English autonomous learning

(1) Maker. Setting learning goals according to students. Influenced by age and environment, students' metacognitive ability and self-monitoring ability are not perfect, and they cannot make perfect goals and plans for self-regulated learning. Teachers should be designed for students' autonomous learning goal of each stage, including listening comprehension, reading ability, vocabulary and grammar level. On this basis, to develop their own personalized learning objectives.

(2) Facilitator. Teachers should promote students' confidence, positive thinking and independent 
study. As a facilitator, teachers should have good personal qualities, profound English knowledge, modern information technology and network technology. With the ability to stimulate students' initiative, help students overcome various obstacles and improve the awareness of autonomous learning, understanding the role of autonomous learning, change the concept of learning, to enable students to become independent learners, self-managed learning.

(3) Coordinator. Teachers should coordinate the environment and atmosphere of English learning so as to enable students to exert their talents freely. Teachers or students' "psychological coordinators" help to form students' useful anxiety and overcome harmful anxiety. Students' learning difficulties, teachers should give them timely guidance and coordination skills, make full use of the limited class time, coordination knowledge and learning strategies teaching, encourage students to explore their own learning strategies.

(4) Organizer. Teachers should be in accordance with the requirements of the syllabus, combined with the actual situation of students, develop the term "reading, writing and translation skills" such as learning tasks, including vocabulary and reading speed, to design a feasible guidance scheme. In view of the individual differences and the basic situation of students, the students can explore the best learning effect and level, and organize the classroom teaching activities according to the content of the teaching and the purpose of the teaching.

(5) Assessor. Teaching evaluation is an important component of teaching activities. Teachers use the positive guiding role of evaluation to combine formative assessment with summative evaluation. The evaluation should be objective, fair and artistic, and often use "good", " so good", "very good", "well done" and other comments. Teachers also help students evaluate themselves, including the level of testing at the beginning of the study, monitoring progress, and peer review.

(6) Provider. Teachers should provide independent learning resources. With the rapid development of Internet and modern educational technology, learning resources are becoming more and more abundant. Teachers can provide English newspapers, magazines and English Learning Websites for students. Teachers also provide students with the language structure, vocabulary, meaning and language knowledge they are familiar with. In the information society, more and more students are not satisfied with the simple knowledge exchange in class. They need teachers to help students develop knowledge, develop language skills and social skills.

\section{Cultivating Strategies on Autonomous Learning Ability in English Teaching}

Guided by the theory of autonomous learning, and aiming at the autonomous learning process and referring to the relevant research results, the strategies for the development of autonomous learning ability in English teaching are as follows:

(1) Cultivate students' awareness of autonomous learning. Quality education is based on students, and students are the masters of learning. In the process of implementing quality education, we should pay attention to the cultivation of students' awareness of autonomous learning, and encourage students to explore and think independently in their teaching activities so as to achieve the best teaching effect. Self-confidence is the key to success in cultivating students' awareness of autonomous learning. In modern educational environment, autonomous learning of College English is largely determined by the students' awareness of autonomous learning. Because of the dual nature of the modern educational environment, many students appear to play games and look at web pages in class. This requires the correct guidance of teachers, to mobilize the enthusiasm of students to learn English, starting from the interests of students, to enhance the students' sense of independent learning.

(2) Actively guide students to study autonomously. The theory of modern education advocates student-centered, emphasizing students' initiative in learning, teachers' role is reflected in the organization, guidance, helper and promoter, give full play to students' initiative, enthusiasm and creativity, to enable students to learn most effectively and achieve the best teaching effect. First, explore boldly and seek new knowledge. The "problem" is the inquiry learning, teachers through the "problem" is put forward, the desire to inspire students to explore new knowledge, guide students to have learning needs in the inquiry process; second, bold questioning, thinking happy. 
Teachers should encourage students to dare to question and boldly express their unique opinions so as to enliven their thinking; third, bold innovation, independent interaction. Organize students to analyze and discuss and stimulate students' creative enthusiasm. Fourth, boldly go and teach yourself independently. So that students really grasp the initiative to learn, to become the master of learning, active and independent participation in learning, and give full play to the main body.

(3) Give full play to the role of process evaluation. Process evaluation is the evaluation in the course of teaching. The purpose of the evaluation is not to select excellent students, but to discover the potential of each student, to strengthen and improve the study, and to provide feedback for teaching. It includes student self-assessment, student evaluation and teacher evaluation of students. Students' self-evaluation, students' ability of their "listening and speaking, reading and writing", etc., has reached to what extent, how to evaluate the expected goal, objective, in order to adjust learning strategies, improve learning methods, improve the efficiency of learning. Students evaluate each other, stand in the students' point of view, evaluate the students' English ability, and overcome the subjectivity of self-evaluation. Teachers evaluate the students, refer to the students' usual assignments, attendance, learning attitudes and autonomous learning records, and observe, supervise and evaluate the students' self-study process to promote their effective learning.

(4) Cultivating metacognitive strategies to promote autonomous learning in English. Metacognitive strategy is that students use metacognitive knowledge to establish learning goals, formulate learning plans, monitor the learning process and evaluate learning effects, so as to achieve the successful steps of foreign language learning. Metacognitive strategies are closely related to autonomous learning ability. Cultivating metacognitive strategies can promote students' autonomous learning ability and accelerate their internalization process. Integrating metacognitive strategies into English learning is the main way to cultivate students' autonomous learning ability. Metacognitive strategies like a bridge, connecting the internal and external metacognitive knowledge of English learning strategies, to enable students to understand their cognitive level, understand the current level of English, selection of learning methods and appropriate materials, monitoring the learning process, so that the metacognitive strategies truly internalized, improve English autonomous learning ability.

\section{References}

[1] L. Zheng, "A Study on Cultivating Strategies of College Students' Autonomous-Learning Ability at the Information Age," Journal of Heilongjiang College of Education, vol. 36, no. 2, pp. 127-129, 2017.

[2] Te-Lien Chou, Lih-Juan ChanLin, "Autonomous ESL Learning: 'Read \& Reflect in English'," Procedia - Social and Behavioral Sciences, vol. 191, no. 2, pp. 357-360, 2015.

[3] H. L. Liang, "How to cultivate students' autonomous learning ability," http://old.pep.com.cn/xxjs/jszj/ktjx/czkt/201008/t20100827_785069.htm, 2017-5-5.

[4] Jorge Martín-Gutiérrez, Peña Fabiani, Wanda Benesova, et al., "Augmented reality to promote collaborative and autonomous learning in higher education," Computers in Human Behavior, vol. 51, no. 2, pp. 752-761, 2015.

[5] H. Y. Li, "Metacognitive strategies and autonomous learning ability of College Students," Heilongjiang Researches on Higher Education, vol. 32, no. 6, pp. 138-140, 2013.

[6] X. Y. Zhang, "Graphic analysis of the process of autonomous language learning," Journal of Hubei University of Economics(Humanities and Social Sciences), vol. 5, no. 6, pp. 183-184, 2008.

[7] Sébastien Hélie, Ron Sun, "Autonomous learning in psychologically-oriented cognitive architectures: A survey," New Ideas in Psychology, vol. 51, no. 2, pp. 752-761, 2014.

[8] Baidu Wenku, "Cultivate students' awareness of autonomous learning," https://wenku.baidu.com/view/f13dbd2be45c3b3567ec8bb6.html, 2017-3-5. 